\title{
Study of the Small and Middle Enterprises Cluster Phenomenon
}

\author{
Huajuan $\mathrm{Wu}^{1}$, Jinfeng $\mathrm{Xu}^{2}$ \\ ${ }^{1}$ Nanchang Institute of Science \& Technology, Nanchang, Jiangxi, 330008
}

KEYWORDS: SME Cluster; Economy Development; Southern and Eastern China

\begin{abstract}
With China's zhejiang special industrial zone and booming Guangdong professional town, our scholars have done some research and have achieved some results, but because of China's economic and high-tech industrial development zone cluster appears late 1990s until the early scale, so the research on the enterprise cluster is still in the trial and exploratory stage, is still mostly limited to foreign cluster theory of general introduction and commentary. We will briefly introduce the relevant research at home and abroad on the basis of defined clusters.
\end{abstract}

\section{Introduction}

After China's implementation of reform and opening-up policy since the early eighties, around the regional economic development is very active in the 1980s in the latter part of the gathering area of township enterprises in Jiangsu and Zhejiang and Guangdong, the rapid rise of the professional town, it attracted wide attention from Chinese scholars and these areas for investigation and research. "Clusters", "Industrial Park", "professional town", "Enterprise Network" has become a hot concept these have appeared, and put forward the "Wenzhou model", "Sunan Mode", "Jiangsu and Zhejiang mode" successful economic development model.

\section{The Importance of the Development of SME Clusters}

Small and Middle Enterprise (SME) Cluster is generally combined with the local historical background, form the basis of natural resources as well as cultural traditions, economic systems on it by absolute advantage, comparative advantage, economies of scale factor endowment or the formation of specialized industrial zones, namely a large number of companies focused on the major industry, production and operation of enterprises, while including the associated class, the class dependent, productive and non-productive infrastructure, improve production efficiency through specialization and cooperation, reduce production costs and improve the competitiveness of the region, and this competitive forces have also not easy to imitate and copy features.

Rooted is the individual or the overall integration of the external environment and adapt to growing businesses cluster only rooted in place, in order to maintain the relative stability and development, attract more new business in the local breeding and growth. It can be said, enterprise clusters embeddedness is a fundamental advantage of the region. Enterprise Cluster strategy not only emphasizes the role of large enterprises in regional development, such as the "big enterprises as the leading SME network" model of development, but also attaches great importance to the role of SMEs in regional development, and even that with respect to SMEs less prone to big business location transplant, more local "rooted", and is the backbone of regional economic development. Due attention to the importance of SMEs and intermediate production, but reliance on big business too much emphasis on the final product or GDP, to avoid the past, some large enterprises and 
regional economic specialization Correlation small problem, which can continue to attract new businesses join and breeding, to produce "multiplier effect" bigger.

In real economic life, the reason why more than 128 Silicon Valley is the rapid development of effective road to its enterprise cluster growth and development, the rapid "Third Italy" is also the rise of its large number of SMEs clusters are inseparable, and in China, the fastest growing economies in the two provinces of Guangdong and Zhejiang, the cluster economic characteristics are very clear, we can say, business clusters is an important source of economic growth and the southeast coast of competitive advantage. Broadly speaking, industrial organization refers to the relationship between morphology and between enterprises within the industry, so it is "micro industrial structure," there is no industrial organization as a carrier, the industrial structure of the allocation of production factors on the "macro" on cannot be achieved, a simple adjustment of the ratio between the industry, but the so-called "macro industrial structure," the change, and "micro industrial structure" has not changed by this adjustment of industrial structure, optimize the goal is difficult to achieve, after adjustment the industrial structure is simply a "virtual optimization" appearance only. Therefore, in order to optimize the industrial structure must be premised on the rationalization of industrial organization.

\section{Current Situation of Enterprise Cluster}

Zhejiang is China's township enterprises, SMEs most concentrated provinces. Dependent on its traditional business culture folk crafts and prosperity to blood, kinship and geographical network as a link to the humanities and the "rather be beheaded without Pteris" the traditional mentality and to make the best use of government and so on, so interdependent clusters rapidly formed. Enterprise Cluster Zhejiang basically belong to the "primitive type", namely, the development of enterprise clusters better combination of local advantages and factor endowments historical and cultural factors, the formation and development has gone through natural selection and evolution of a historical process, with a very strong vitality and development potential. Currently, Zhejiang Province has become the main areas such as Ningbo garment industry in Haining City as the center of the leather industry in Shaoxing region as the center of textile industry in Wenzhou and Taizhou in the center of the shoe, lighters, wool processing industry, centered in Yongkang hardware industry in the region as the main Jiaxing- Huzhou silk processing industry, Shengzhou tie, Zhuji Hosiery and other clusters.

Guangdong's economy grew rapidly in the past 20 years, a significant phenomenon is that a large number of professional town (clusters) up economic development. According to statistics, the province's 1551 municipal towns, the total production of over 1 billion yuan of social town has 274, including the Pearl River Delta region accounted for 194, all the towns in the region of $46 \%$, these towns are mostly professional production of the product / service and the formation of business clusters, showing "one town one industry, the one village one product" feature of the economic structure. Zhejiang "native" enterprise clusters is different from the formation and development of Guangdong Enterprises Cluster motives, forms showing diversity, some scholars Guangdong Enterprises Cluster depict three forms: clusters (native type) formed by history, along global commodity value chains formed clusters (embedded) clusters and innovation networks. From the power source cluster formation, the bottom has formed a professional civil power economy town featured cluster, mainly in the Pearl River Delta area as well as to promote the formation of export-oriented foreign-oriented processing enterprises cluster. From the mainstream view, foreign investment is still "embedded" business clusters based. 


\section{Enterprise Cluster Development Problems}

Thanks to innovative investment risks, external and strong R \& D investments in order to reduce costs and reduce the risk of innovation, technology imitation motive cluster innovation far exceeds its motive, within the group of SMEs are willing to become "free riders" rather than independent innovation. At present, this type of business clusters widespread lack of technological innovation motivation affecting industrial upgrading issues.

Most companies basically plant shabby, outdated equipment and backward technology, small-business workshops. And the production is very fragmented, and the cluster lacks the necessary degree of organization and coordination, often resulting in lower prices Price Competition enterprises, fake, shoddy reduce the quality standards, product highly homogeneous caused by disorderly competition is very serious. For example, the production of Yueqing $10 \mathrm{~cm}$ twist from \$ 2 per head falls below the cost price of 0.53 yuan; Yongkang angle grinder produced by the 130 yuan each dropped guaranteed even at a loss price of 82-78 yuan, only the sales price of similar foreign products homogeneity of $1 / 2$ to $1 / 3$.

Many business owners conduct of operations within the cluster of serious short-term presence, quality and brand consciousness. Many companies do not have the case registered trademark, trademark counterfeiting others produced repeated. Some cluster enterprise product of poor quality, low grade, not only damages the credibility of the enterprise, and even result in a poor image of the entire enterprise and regional clusters to become synonymous with inferior products, those products as well as good quality and high grades, the company did not dare beat local brands, have a "Gresham's Law" phenomenon seriously affected the sustained development of local economy.

The path of development, Dongguan has a certain universal significance in the southeast coast. Enterprise clusters in the industrialization process of the formation of Dongguan, spanning primitive accumulation of capital of European classical period experienced local enterprise clusters, and direct foreign trade to local industrial capital, starting from the low-cost advantage to develop export-oriented economy, which local production chain integrity of a type of enterprise cluster is not high. Although 95\% of computer parts can be found in Dongguan, but the core parts such as CPU, hard drive, memory and so on but not in Dongguan, production, and research and development, sales, purchasing and other areas are in the field, Dongguan purely a processing base; at the same time , industry concentration is low, fierce competition in a limited monopoly, the final manufacturer of the same type of accessory or an external device or more, and the product is technically the difference is not. Guangzhou and Shenzhen City computer hardware staged a round of price wars largely reflects the characteristics of the industry.

\section{The Policy to Develop SEM Cluster}

Local government as a "broker network" businesses in the region meet regularly convene a public meeting to discuss the development of local enterprises constraints "bottleneck." Within the cluster, companies often face the same or similar problems, to solve the problem also has significant economies of scale, We can work together by the SMEs. For example: common procurement of raw materials, to jointly build products wholesale or retail establishment, jointly introduce new production equipment, have completed a large order of production, to develop a new technology, the use of a common trademark, together constitute a collective guarantee mechanism to bank loans, joint use of certain production facilities, joint education and training program, jointly environmental pollution and so on. Local government as "network broker" to provide opportunities for SMEs to 
conduct joint operations, but is also a contributing among SMEs, and gradually establish a trust relationship between SMEs and local government processes.

To create this environment, regional innovation, clusters need to have the required hard and soft industry environment. Hard environment is modern infrastructure, convenient transportation and communication, supporting production and service facilities. Soft environment contains three levels: (1) Institutional environment. Including the area between the main innovation institution-building and institutional linkages. Such as banks and other financial institutions for the financial services, talent exchange centers to labor mobility services, to strengthen exchanges and cooperation with industry personnel and other industry associations. (2) Medium environment. Including the people's cultural level, values. (3) Environmental regulation. It refers to the government to play the role of macro-control, so that a plurality of subject related innovative synergy occurs.

Regional development under the principle of Knowledge Economy, based on the comparative advantages of the original resource endowment formation, development to the present innovation ability based on dynamic competitive advantage. And an important basis for continued innovation, is to rely on local enterprises and between enterprises and between enterprises and institutions supporting the formation of cluster innovation networks, creating an innovative environment for enterprises to technological innovation services.

\section{Conclusion}

In modern economic development, domestic and international experience proves the competitiveness of the region depends on the competitiveness of the industry. The emergence and development of industrial clusters to enhance the competitiveness of the regional industry, and promote the rapid and healthy development of regional economy. After joining WTO, the higher the degree of internationalization of China's economic development, in the face of fierce competition in the international market, SMEs through cluster development, and enhance their competitiveness. Thus, cultivating local industrial clusters, capacity-building for sustainable development in the region, it is an effective way to achieve regional economic competitiveness of the national economy as a whole increased.

\section{Reference:}

[1] Michael E. Porter. Clusters and the New Economics of Competition [J]. Harvard Business Review, 1998, (12): 77-90.

[2] Markusen A. Sticky places in slippery space:. A typology of industrial districts [J]. Economic Geography. 1996 (2):. 293-294.

[3] Maillat D. Territorial dynamic, innovative milieu and regional policy [J] .Entrepreneurship and regional Development. 1995 (7): 157-163.

[4] Piero Morosini. Industrial clusters, knowledge integration and performance [J]. World Development, 2003:. 305-326.

[5] Sven Hem Lin Creative Knowledge Environments in The Innovation System Copenhagen [J] .Copenhagen Business School Working Paper, 2001 (7): 1-14. 